\title{
CONHECIMENTO DE PUÉRPERAS INTERNADAS EM UM ALOJAMENTO CONJUNTO ACERCA DA HIGIENE DO NEONATO
}

Lucilande Cordeiro de Oliveira Andrade ${ }^{1}, M_{a r c o s}$ Silva dos Santos ${ }^{2}$,Julliana dos Santos Aires ${ }^{3}$, Emanuella Silva Joventino $^{4}$, Regina Cláudia Melo Dodt ${ }^{5}$, Lorena Barbosa Ximenes ${ }^{6}$

RESUMO: Objetivou-se avaliar o conhecimento materno acerca dos cuidados de higiene prestados ao recém-nascido. Estudo descritivo e transversal realizado com 150 puérperas do alojamento conjunto de uma maternidade de Fortaleza- Ceará. Os dados foram coletados, entre janeiro e abril de 2010, por meio de entrevistas e analisados com auxílio de estatística descritiva. Verificou-se maior conhecimento das puérperas acerca da frequência do banho e da temperatura da água, sequência de execução do banho, material para higiene íntima, fixação da fralda, frequência da limpeza do coto umbilical e necessidade de higienização oral. A maioria desconhecia não ser necessário higienizar os mamilos antes da mamada, os produtos para banho, sequência para higienizar a região íntima, cobertura do coto e produtos para higienização deste. Ressalta-se a importância das atividades educativas do enfermeiro no pré-natal e puerpério que auxiliem as mães nos cuidados de higiene do recém-nascido. PALAVRAS-CHAVE: Saúde da criança; Higiene; Enfermagem; Comportamento materno; Alojamento conjunto.

\section{NEW MOTHERS' KNOWLEDGE ABOUT HYGIENE FOR NEW-BORNS}

ABSTRACT: This descriptive, transversal study aimed to evaluate mothers' knowledge about measures of hygiene applied to new-borns. It was carried out with 150 women who had recently given birth in a maternity ward in the city of Fortaleza in the state of Ceará. The data was collected between January and April 2010 through interviews, and was analyzed with the aid of descriptive statistics. It was ascertained that the new mothers knew most about frequency of bathing and bathwater temperature, the sequence of events involved in bathing a new-born, products for 'tailing' the baby (washing its bottom and genitals), putting on the diaper, frequency of cleaning the umbilical stump and the necessity for oral hygiene. The majority were unaware that it is not necessary to thoroughly clean the nipples before breast-feeding and about bath products, the sequence involved in cleaning the bottom and genitals, covering of the umbilical stump, and products for cleaning it. The study emphasizes the importance of nurse-led educational activities in the pre-natal and post-partum periods to help mothers with hygiene care of the new-born. KEYWORDS: Child health; Higiene; Nursing; Maternal behavior; Rooming-in care .

\section{CONOCIMIENTO DE PUÉRPERAS SOBRE LA HIGIENE DEL NEONATO}

RESUMEN: Se objetivó evaluar el conocimiento materno acerca de los cuidados de higiene prestados al recién nacido. Este estudio descriptivo y transversal fue realizado con 150 puérperas del alojamiento conjunto de una maternidad de Fortaleza Ceará. Los datos fueron recogidos, entre enero y abril de 2010, por medio de entrevistas y analizados con ayuda de estadística descriptiva. Se verificó mayor conocimiento de las puérperas acerca de la frecuencia del baño y de la temperatura del agua, secuencia de execucion del baño, material para higiene íntima, fixación del pañal, frecuencia de la limpieza umbilical y necesidad de higienización oral. La mayoría desconocia no ser necesario higienizar los pezones antes de la mamada, sobre productos para baño, secuencia para higienizar la región íntima, cobertura del ombligo y productos para higienización de este. Se destaca la importancia de las actividades educativas del enfermero en el prenatal y puerperio que ayuden las madres en los cuidados de higiene del recién nacido.

PALABRAS-CLAVE: Salud del niño ; Higiene; Enfermería; Comportamiento materno; Alojamiento conjunto.

\footnotetext{
${ }^{1}$ Enfermeira da Estratégia Saúde da Família da Secretaria Municipal de Fortaleza. Especialista em Enfermagem Neonatológica. ${ }^{2}$ Acadêmico de Enfermagem da Faculdade Metropolitana da Grande Fortaleza - FAMETRO.

${ }^{3}$ Enfermeira. Mestranda do Programa de Pós-Graduação em Enfermagem da Universidade Federal do Ceará - UFC.

${ }^{4}$ Enfermeira. Mestre em Enfermagem. Doutoranda pelo Programa de Pós-Graduação em Enfermagem da UFC. Bolsista CNPq. ${ }^{5}$ Enfermeira. Mestre em Enfermagem. Doutoranda pelo Programa de Pós-Graduação em Enfermagem da UFC.

${ }^{6}$ Enfermeira. Doutora em Enfermagem. Professora pelo Departamento de Enfermagem da UFC. Coordenadora do Programa de PósGraduação em Enfermagem da UFC. Pesquisadora do CNPq.
} 


\section{INTRODUÇÃO}

A criança, devido à imaturidade do seu sistema imunológico sobretudo no período neonatal, necessita de atenção especial e monitoramento cuidadoso da sua saúde; é totalmente dependente do cuidado de terceiros sendo premente considerar o conhecimento e a maneira como a família a cuida, principalmente quando se trata de recém-nascidos.

A mãe, culturalmente, é a pessoa que presta cuidados aos demais membros da família, sendo imprescindível que tenha conhecimentos acerca dos cuidados básicos que os recém-nascidos demandam relacionados principalmente à higiene, à alimentação e à segurança.

Estudos demonstram que a ineficácia do cuidar em relação aos hábitos de higiene pode estar relacionada com o adoecimento das crianças, como aquisição de enteroparasitoses ${ }^{(1)}$, problemas dentários ${ }^{(2)}$, escabiose e pediculose ${ }^{(3)}$. Ressalta-se que a adequação do cuidado pode depender das habilidades do cuidador da criança, geralmente a mãe, e da intersubjetividade em que se encontra inserido. A mãe necessita tornar-se empoderada para executar cuidado de qualidade para a criança, bem como promover a sua saúde por meio de responsabilidade compartilhada com os profissionais de saúde.

Contudo, sabe-se que em muitos casos predomina a insegurança da mãe em prestar cuidados, sobretudo relacionados aos hábitos de higiene, como troca de fraldas e banho do recém-nascido, ocasionada, em alguns casos, pela falta de orientação profissional no momento da alta hospitalar da criança. Assim, tornase premente que a mãe inicie a cuidar do seu filho durante a hospitalização, para que possa aprender algo que venha minimizar as dificuldades de cuidado no ambiente domiciliar ${ }^{(4)}$.

Com o intuito de possibilitar a prestação de todos os cuidados assistenciais, bem como a orientação da mãe sobre a saúde do binômio mãe e filho, foi criado o sistema de Alojamento Conjunto, no qual o recémnascido sadio, logo após o nascimento, permanece ao lado da mãe, 24 horas por dia, em um mesmo ambiente, até a alta hospitalar ${ }^{(5)}$. Neste serviço, os profissionais que assistem ao binômio mãe-filho, além de poderem contar com a colaboração das puérperas, prestam orientações acerca dos cuidados dispensados aos neonatos, fazendo com que as mães sintam-se mais seguras quando receberem alta hospitalar.

$\mathrm{Na}$ assistência ao neonato, muitos cuidados pres- tados dizem respeito à pele, pois as lesões deste órgão predispõem o recém-nascido ao risco de adquirir infecções, podendo ainda causar sequelas e cicatrizes, sendo necessário, na assistência de enfermagem, constantes avaliações, visando a prevenção destes danos ${ }^{(6)}$.

Diante disto, é necessário que os enfermeiros orientem as puérperas no alojamento conjunto com o intuito de minimizar os agravos à saúde do neonato. Nesse sentido, objetivou-se neste estudo avaliar o conhecimento materno acerca dos cuidados de higiene do recém-nascido.

\section{MÉTODO}

Trata-se de um estudo descritivo, transversal, com abordagem quantitativa, realizado com puérperas que se encontravam internadas no alojamento conjunto de uma maternidade pública de referência em Fortaleza, Ceará, no período de janeiro a abril de 2010. A amostra foi composta por 150 puérperas, número obtido por meio do cálculo para populações finitas, as quais foram selecionadas por conveniência, de acordo com a demanda da maternidade no período da pesquisa.

Os critérios de inclusão dos sujeitos foram: puérperas com idade superior a 18 anos mães de neonatos a termo e peso adequado ao nascer de crianças a termo. Os critérios de exclusão foram: puérperas que apresentassem patologias que impedissem ou colocassem em risco a presença do recém-nascido em alojamento conjunto, tais como doença mental grave ou doenças infectocontagiosas.

A coleta de dados se deu por meio de entrevistas individualizadas realizadas nas enfermarias onde as puérperas encontravam-se internadas, para tanto, utilizou-se um formulário abordando dados sociodemográficos e obstétricos, bem como itens relacionados à higiene do recém-nascido. Os dados foram tabulados e processados por meio do programa Statistical Package for the Social Sciences (SPSS Inc., Chicago, Estados Unidos), versão 17.0. Para a análise, valeu-se da estatística descritiva, por meio de frequências absolutas e relativas, sendo analisados de acordo com a literatura pertinente.

A pesquisa foi aprovada pelo Comitê de Ética em Pesquisa da Maternidade onde o estudo foi realizado, sob parecer n. 46/08. Foram respeitadas todas as recomendações e requisitos éticos previstos na Resolução 196/96 que versa sobre atividades de pesquisa envolvendo seres humanos. 


\section{RESULTADOS}

Observou-se que das 150 mães envolvidas no estudo, a maioria tinha entre 18 e 25 anos $(82 ; 54,7 \%)$, renda familiar entre 1 e 3 salários mínimos (127;84,6\%), com ensino fundamental completo ou incompleto $(81 ; 54 \%)$, viúva, divorciada ou vivia em união consensual $(91 ; 60,7 \%)$ e não possuía ocupação formal, sendo dona de casa $(94 ; 62,7)$.

Quanto às condições de moradia, prevaleceram os domicílios com 4 a 6 cômodos (104;69,3\%), 2 a 4 moradores (78;52\%), com abastecimento de água $(140 ; 93,3 \%)$ e destino do lixo realizado pela rede pública $(142 ; 94,7 \%)$. A maioria das puérperas referiu que a família consumia água tratada, pois compravam a água mineral industrializada $(80 ; 53,3 \%)$, enquanto que $14(9,3 \%)$ mencionaram não realizar nenhum tratamento na água antes do consumo.

Destaca-se ainda o fato de que a maioria das puérperas entrevistadas era multípara $(87 ; 58 \%)$ e que nesta última gestação pariram recém-nascidos a termo $(150 ; 100 \%)$, com valores de APGAR maiores ou iguais a 7 , tanto no primeiro minuto (145;96,7\%), quanto no quinto minuto $(149 ; 99,3 \%)$ de vida.

Em relação aos cuidados de higiene prestados aos neonatos no banho, de acordo com a Tabela 1 , verificou-se maior conhecimento das puérperas acerca da temperatura ideal da água, frequência do banho e da lavagem do couro cabeludo, bem como sobre a sequência de execução do banho; enquanto que 104 (69,3\%) mães demonstraram desconhecimento sobre os produtos de higiene adequados para o banho do recém-nascido.

Quanto à troca de fralda e higiene íntima do neonato (Tabela 2), as puérperas tinham conhecimento adequado sobre o material indicado para a higiene da região íntima do recém-nascido na hora da troca de fraldas $(122 ; 81,3 \%)$ e sobre a maneira de fixar a fralda137(91,3\%). Destarte, a maioria $83(55,3 \%)$ não sabiam a sequência da higienização da região íntima, principalmente em relação às crianças do sexo feminino.

Acerca da limpeza do coto umbilical (Tabela 3) a maioria conhecia sobre a frequência da higienização, limpeza após a queda do coto e sobre a sensação do recém-nascido no momento da higiene do coto. No entanto, a maioria 90(60\%) acreditavam na necessidade de cobertura do coto com curativos ou faixas e desconheciam os produtos adequados para esta higienização $81(54 \%)$.

A maioria das mães respondeu equivocadamente que há necessidade de higienizar seus mamilos antes da mamada (128; 85,3\%), contudo demonstraram conhecimento quanto à higiene oral da criança após cada amamentação $(125 ; 83,3 \%)$, à lavagem das roupas do recém-nascido separadamente às dos demais membros da família $(148 ; 98,7 \%)$ e sobre os produtos que devem ser utilizados $(144 ; 96 \%)$.

\section{DISCUSSÃO}

No presente estudo observou-se que a maioria das puérperas era adulto-jovem, fato que pode influenciar nos cuidados prestados aos filhos. Sabe-se que a idade materna mais jovem pode estar relacionada com uma inadequada interpretação e assimilação dos conhecimentos referentes à assistência às crianças, pois mães mais jovens convivem com algumas dificuldades como menor grau de escolaridade, poder aquisitivo mais baixo e a inexistência de união conjugal estável. Além disso, estas mulheres tendem a aliar sua insegurança para promover os cuidados essenciais aos seus bebês, à falta de apoio dos familiares, aos conflitos da maternidade, bem como ao egocentrismo, muitas vezes característico da juventude ${ }^{(7)}$.

Quanto à ocupação, como a maioria das mães relatou não possuir ocupação formal, portanto, não contribuem com a renda familiar, implicando, em alguns casos, para uma baixa renda per capita, já que muitos domicílios contam com número elevado de moradores. Este achado pode influenciar também nas condições de vida e de moradia da família, desde aspectos relacionados à alimentação, ao acesso à saúde, abastecimento de água e saneamento básico ${ }^{(8)}$.

Convém destacar que, apesar da faixa etária materna jovem, o número de mulheres multíparas foi de $58 \%$, achado que corrobora com estudos que apontam que cerca de um terço das mulheres na faixa etária de $15 \mathrm{a}$ 24 anos já são mães, e 13,8\% delas têm o segundo filho na faixa etária de 20 a 24 anos, sugerindo início precoce da maternidade ${ }^{(9)}$. Tal fato pode facilitar o estabelecimento de maior segurança nos cuidados prestados aos seus próximos filhos, caso estas mães multíparas tenham vivenciado experiências anteriores positivas ${ }^{(7)}$.

Pode-se identificar também que a totalidade das crianças, cujas mães participaram do presente estudo, era a termo e possuía bom nível de vitalidade, achados relevantes tendo em vista que pode evidenciar associação com a maturidade dos seus sistemas e órgãos, inclusive da pele, que apresenta uma propriedade de barreira de proteção da criança às lesões tissulares ${ }^{(10)}$.

Quanto aos cuidados de higiene investigados, o ba- 
Tabela 1 - Conhecimento das puérperas sobre os cuidados higiênicos prestados aos recém-nascidos. Fortaleza, 2010

\begin{tabular}{lcc}
\hline \multicolumn{1}{c}{ Variáveis } & N & \% \\
\hline Banho - Temperatura indicada da água & 107 & 71,3 \\
Certo & 43 & 28,7 \\
Errado & 144 & 96 \\
Banho - Frequência do Banho & 6 & 4,0 \\
Certo & & \\
Errado & 46 & 30,7 \\
Produtos de higiene adequados para o banho & 104 & 69,3 \\
Certo & & \\
Errado & 89 & 59,3 \\
Frequência da lavagem do couro cabeludo & 61 & 40,7 \\
Certo & & \\
Errado & 123 & 82 \\
Sequência de execução do banho & 27 & 18 \\
Certo & & \\
Errado & &
\end{tabular}

Tabela 2 - Conhecimento das puérperas sobre troca de fraldas e higiene íntima dos recém-nascidos. Fortaleza, 2010

\begin{tabular}{lcc}
\hline \multicolumn{1}{c}{ Variáveis } & N & \% \\
\hline Material indicado para a higienização da região íntima do recém-nascido & \\
Certo & 122 & 81,3 \\
Errado & 28 & 18,7 \\
Fixação da fralda & 137 & 91,3 \\
Certo & 13 & 8,7 \\
Errado & 67 & 44,7 \\
Sequência da higienização da região íntima de acordo com o sexo da criança & 55,3 \\
Certo & 83 & \\
Errado &
\end{tabular}

Tabela 3 - Conhecimento das puérperas sobre limpeza do coto umbilical dos recém-nascidos. Fortaleza, 2010

\begin{tabular}{lcc}
\hline \multicolumn{1}{c}{ Variáveis } & N & \% \\
\hline Frequência da higienização por dia & 103 & 68,7 \\
Certo & 47 & 31,3 \\
Errado & & 40,0 \\
Necessidade de cobertura do coto com curativos ou faixas & 60 & 60,0 \\
Certo & 90 & \\
Errado & 121 & 80,7 \\
Higienização da região umbilical após queda do coto & 29 & 19,3 \\
Certo & 119 & 79,3 \\
Errado & 31 & 20,7 \\
Percepção de dor no recém-nascido durante a sua higienização \\
Certo \\
Errado
\end{tabular}


nho do recém nascido visa, especialmente, as zonas que necessitam de maior atenção, como face, pescoço, pregas e área das fraldas. A duração do banho deve ser curta e a frequência varia conforme a cultura de cada localidade, ademais a temperatura da água deve sempre estar próxima à temperatura corporal ${ }^{(11)}$. Contudo, algumas puérperas acreditam que não se deve banhar a criança antes da queda do coto umbilical, fator que aliado à fragilidade $\mathrm{e}$ à sensibilidade do neonato, contribuem para que as mães sintam-se temerosas em segurá-lo para banhá-lo ${ }^{(12)}$.

Apesar disso, o presente estudo demonstrou que a maioria das mães possui conhecimento adequado sobre os aspectos relacionados ao banho. Estudo realizado no sul do Brasil verificou que as mães entrevistadas tinham conhecimentos básicos sobre as necessidades de higiene corporal de seus filhos, apesar disso, as crianças chegavam nas creches em condições inadequadas de higiene ${ }^{(3)}$. Diante disso, mesmo sabendo-se que apenas o conhecimento não é suficiente, acredita-se que este seja essencial para que as mães possam superar suas dificuldades e inseguranças, favorecendo a adesão a práticas promotoras de saúde em seu cotidiano.

No entanto, ainda quanto ao banho, identificou-se conhecimento deficiente entre as mães em relação aos produtos de higiene que devem ser utilizados, resultando no uso de artigos com fragrâncias e de talco. Destaca-se que o uso de produtos de higiene no neonato deve ser feito de forma moderada, preferindo-se aqueles que sejam indicados para crianças, líquidos, suaves, sem fragrância, com pH neutro, tendo em vista que a pele do recém-nascido sofre um progressivo processo de adaptação ao ambiente extrauterino, é sensível, frágil, de $\mathrm{pH}$ neutro, fatores que associados reduzem a defesa do organismo contra a proliferação microbiana, sendo necessários cuidados especiais ${ }^{(11)}$.

Quanto à troca de fraldas, as puérperas demonstraram possuir conhecimento adequado em relação ao material indicado para higienização da região íntima do recém-nascido e maneira adequada de fixar a fralda. As fraldas devem ser trocadas frequentemente, evitandose deixar a criança úmida por longos períodos, fato que expõe a criança a microorganismos e infecções ${ }^{(13)}$.

A higienização da região genital do neonato, quando o mesmo apresentar eliminações vesicais, deve ser realizada com água morna e algodão, dispensando-se o uso de sabonetes. Entretanto, quando for o caso de evacuações intestinais, recomenda-se o uso de sabonetes com pH neutro, sendo desnecessário recorrer a preparações tópicas para prevenir dermatite da área das fraldas ${ }^{(11)}$, exceto em casos indicados pelos próprios profissionais de saúde.
Acerca da limpeza do coto umbilical, a maioria das puérperas acreditava ser necessária a cobertura do coto com curativos ou faixas e desconheciam os produtos adequados para esta higienização. Destaca-se que ainda existem, em algumas populações, hábitos culturais arraigados, muitas vezes passados por avós, acerca dos cuidados prestados às crianças, como recomendações de colocar sobre o coto banha de galinha, faixas umbilicais ${ }^{(14)}$, café, arruda, folha de fumo e moeda ${ }^{(15)}$.

A limpeza do coto umbilical é uma medida importante na prevenção de onfalites causadas por microorganismos que podem evoluir para sepse, levando até mesmo ao óbito da criança. Estudo afirma que a limpeza do coto umbilical com clorexidine, até a sua queda, é capaz de reduzir o risco de infecção e, consequentemente, de morte do neonato ${ }^{(16)}$. No Brasil, o Ministério da Saúde orienta que o cuidador higienize suas mãos e utilize uma gaze para secar a base do coto. Em seguida, deve embeber em álcool $70 \%$ outra gaze e aplicar sobre o coto, em sua base. Isso deve ser repetido a cada troca de fralda ${ }^{(17)}$.

No que diz respeito à higienização relacionada à amamentação, neste estudo identificou-se que $85,3 \%$ das mulheres afirmaram que énecessário higienizar os mamilos antes da mamada. Contudo, conforme orientações do Ministério da Saúde ${ }^{(18)}$, a mama não precisa ser limpa antes ou após as mamadas, sendo suficiente o banho diário da mãe.

Ademais, a maioria das puérperas entrevistadas reconheceu a necessidade da higiene bucal do recémnascido, corroborando com o estudo desenvolvido com 250 pais de crianças de quatro creches de Porto AlegreRS, o qual evidenciou que $98 \%$ destes consideravam importante a higienização oral do recém-nascido ${ }^{(19)}$. Sabe-se que a higiene oral deve começar a partir do nascimento da criança, devendo ser realizada com uma gaze ou fralda umedecida em água potável para remover os resíduos de leite materno, pelo menos uma vez ao dia, preferencialmente à noite ${ }^{(17)}$.

Por sua vez, quanto à lavagem de roupas do recémnascido, quase a totalidade das puérperas possuía conhecimento adequado. Recomenda-se que seja utilizado sabão em pedra neutro, de preferência, sabão de côco para a lavagem das roupas da criança, devendo ser evitado o uso excessivo de sabão em pó e amaciante, pois estes possuem composição química que adere nas fibras das roupas e que, no contato com a pele da criança, podem causar alergias. É importante ainda que as roupas sejam secadas ao sol, passadas a ferro para eliminar possíveis microorganismos ${ }^{(20)}$ e que sejam lavadas separadamente das roupas dos demais membros da família. 


\section{CONCLUSÃO}

Por meio do presente estudo pode-se observar a necessidade de esclarecimentos às mães acerca de alguns cuidados higiênicos específicos aos recém-nascidos.

Verificou-se que as puérperas participantes demonstraram desconhecimento sobre os produtos de higiene adequados para o banho do recém-nascido, sobre a sequência da higienização da região íntima de acordo com o sexo da criança, sobre o uso de curativos, faixas e os produtos recomendados para higienização do coto umbilical. Destaca-se ainda que a maioria das mães não sabia ser desnecessário limpar os mamilos antes das mamadas.

Nesse sentido, faz-se premente a atuação efetiva da equipe multiprofissional, sobretudo do enfermeiro, na realização de consultas pré-natais de qualidade e na prestação de orientações sobre a higiene da criança no período puerperal, seja quando o binômio ainda se encontra na maternidade, seja nas consultas de puerpério subsequentes. Para tanto, é fundamental o desenvolvimento de estratégias de educação em saúde que auxiliem na prestação dos cuidados aos recém-nascidos, devendose enfatizar os principais aspectos identificados como causadores de dúvidas nas mães. Dessa forma, esses profissionais estarão promovendo a saúde infantil.

\section{REFERÊNCIAS}

1. Pereira IV, Cabral IE. Diarreia aguda em crianças menores de um ano: subsídios para o delineamento do cuidar. Esc Anna Nery. 2008;12(2):224-9.

2. Neves BG, Pierro VSS, Maia LC. Percepções e atitudes de responsáveis por crianças frente ao uso de medicamentos infantis e sua relação com cárie e erosão dentária. Ciênc. saúde coletiva. 2007;12(5):1295-300.

3. Remor CB, Pedro VL, Ojeda BS, Gerhardt LM. Percepções e conhecimentos das mães em relação às práticas de higiene de seus filhos. Esc Anna Nery. 2009;13(4):786-92.

4. Wust GG, Viera CS. O relacionamento mãe-bebê pré-termo após a alta hospitalar. Cogitare enferm. 2011;16(2):311-8.

5. Patine FS, Furlan MFFM. Diagnósticos de enfermagem no atendimento a puérperas e récem-nascidos internados em alojamento conjunto. Arq. ciências da Sáude. 2006;13(4): 202-8

6. Nepomuceno LMR. Avaliação do indicador de qualidade "Integridade da Pelo do Recém-Nascido" como subsídio para a capacitação do pessoal de enfermagem [dissertação]. São Paulo(SP): Universidade de São Paulo; 2007.

7. Oliveira JS, Joventino ES, Dodt RCM, Veras JEGLF, Ximenes LB. Fatores associados ao desmame precoce entre multíparas. Rev. RENE. 2010;11(4):95-102.

8. Odinino NG, Guirardello EB. Satisfação da puérpera com os cuidados de enfermagem recebidos em um alojamento conjunto. Texto \& contexto enferm. 2010;19(4):682-90.

9. Instituto Brasileiro de Geografia e Estatística (IBGE). Ministério do planejamento, orçamento e gestão: $\mathrm{O}$ perfil da mulher jovem de 15 a 24 anos, características diferenciais de desafios [Internet] 2000. [acesso em 29 jun 2011 ]. Disponível: http://www.ibge.gov.br/home/estatistica/ populacao/populacao_jovem_brasil/comentario2.pdf

10. Gurgel EPP. O uso da membrana semipermeável como proteção da pele do recém-nascido prematuro [dissertação]. Fortaleza (CE): Universidade Federal do Ceará; 2008.

11. Fernandes JD, Machado MCR, Oliveira ZNP. Prevenção e cuidados da pele da criança e do recém-nascido. An. bras. dermatol. 2011;86(1):102-10.

12. Bergamaschi SFF, Praça NS. Vivência da puérperaadolescente no cuidado do recém-nascido, no domicílio. Rev. esc. enferm USP. 2008;42(3):454-60.

13. Fontenele FC, Cardoso MVLML. Lesões de pele em recém-nascidos no ambiente hospitalar: tipo, tamanho e área afetada. Rev esc. enferm. USP. 2011 Mar; 45(1):1307.

14. Iserhard ARM, Budó MLD, Neves ET, Badke MR. Práticas culturais de cuidados de mulheres mães de recém-nascidos de risco do sul do Brasil. Esc. Anna Nery. 2009;13(1):116-22.

15. Silva LR, Christoffel MM, Castro SJ, Ribeiro F. A prática do cuidado prestado pelas mulheres aos filhos no domícilio. Enfermería global. 2007;10:1-9.

16. Mullany LC, Darmstadt GL, Katz J, Khatry SK, LeClerq SC, Adhikari RK, et al. Risk Factors for Umbilical Cord Infection among Newborns of Southern Nepal. Am. j. epidemiol. 2007;165(2):203-11.

17. Ministério da Saúde (BR). Secretaria de Atenção à Saúde. Departamento de Ações Programáticas Estratégicas.

Cogitare Enferm. 2012 Jan/Mar; 17(1):99-105 
Manual para a utilização da caderneta de saúde da criança. Brasília: Ministério da Saúde; 2005.

18. Ministério da Saúde (BR). Secretaria de Atenção à Saúde. Promovendo o Aleitamento Materno. $2^{\mathrm{a}}$ ed. Brasília: Ministério da Saúde; 2007.

19. Guarienti CA, Barreto VC, Figueiredo MC. Conhecimento dos pais e responsáveis sobre saúde bucal na primeira infância. Pesq. bras. odontoped. clin. integr. 2009;9(3):321-5.

20. Fonseca LMM, Scochi CGS. Cuidados com o bebê prematuro: orientações para a família. $2^{\mathrm{a}}$ ed. Ribeirão Preto: FIERP; 2005. [acesso em 24 out 2011]. Disponível: http://bvsms.saude.gov.br/bvs/publicacoes/ Cartilha_cuidados_bebe_premat.pdf 